\title{
Cutting Parameters for Roughing Turning of Alloy 625 Clad Using Ceramic Inserts
}

\author{
Gabriel Krebs ${ }^{a}$, Milton Luiz, Polli ${ }^{a} *$ [D
}

\author{
${ }^{a}$ Universidade Tecnológica Federal do Paraná (UTFPR), Rua Deputado Heitor Alencar Furtado, 5000, \\ Campo Comprido, CEP 81280-340, Curitiba, PR, Brasil
}

Received: September 23, 2019; Accepted: November 02, 2019

\begin{abstract}
Nickel alloy 625 is widely used in submarine equipment for the oil and gas industry, which operate in an extremely adverse environment. In order to reduce the costs of these components, weld overlay cladding is employed. The surface generated by this process presents some irregularities that represent an additional difficulty to the machining process. The present work investigates the use of whiskers-reinforced ceramic tools and SiAlON in turning of alloy 625 clad on AISI 4130 steel by an automatic tungsten inert gas (TIG) cladding system. The results indicate the feasibility of the industrial application of the SiAlON inserts in rough turning of the alloy 625 clad, as well as the impossibility of using whiskers-reinforced ceramic tools $(\mathrm{Al} 2 \mathrm{O} 3+\mathrm{SiCw})$ in the same conditions. The highest flank and notch wear of the SiAlON inserts were observed for the lowest cutting speed $(140 \mathrm{~m} / \mathrm{min})$, which induced the formation of burrs in the workpiece at the depth of cut. Adhesion occurred more intensively at this condition. The least flank and notch wear were achieved by using cutting speed of $160 \mathrm{~m} / \mathrm{min}$ and feed-rate of $0.25 \mathrm{~mm} / \mathrm{rev}$. Prolonged turning with worn tools resulted in microstructural alterations of the workpiece material and surface damages.
\end{abstract}

Keywords: alloy 625, turning, tool wear, ceramic.

\section{Introduction}

The nickel based superalloys contain $38-76 \% \mathrm{Ni}$ and up to $28 \%$ of each of the $\mathrm{Cr}$, Co and Mo elements and are basically composed of three distinct classes: reinforced, precipitation curable and oxides dispersion (ODS) solid solution. Solid solution alloys contain little or no $\mathrm{Al}$, Ti or $\mathrm{Nb}$. Precipitation curable alloys contain high percentage of $\mathrm{Al}$ and $\mathrm{Ti}$, and some contain $\mathrm{Nb}$. ODS alloys contain a small amount of fine oxide particles $\left(0.5\right.$ to $\left.1 \% \mathrm{Y}_{2} \mathrm{O}_{3}\right)$ and are produced by powder metallurgy techniques ${ }^{1,2}$. The nickel-based superalloys are characterized as having high mechanical strength when subjected to high temperatures, high abrasiveness due to the chemical components that make up this alloy, high ductility and toughness ${ }^{3-5}$. These alloys have characteristics that define them as difficult to machine materials when compared to steels with the same properties at room temperature, because they maintain high mechanical strength at high temperatures ${ }^{6}$. However, the machining of nickel base alloys can be achieved, provided that the fundamental principles that affect its machinability are understood and taken into account ${ }^{7}$.

Alloy 625 is strengthened mainly by the solid solution hardening effect of niobium and molybdenum in a nickelchromium matrix ${ }^{1}$. It is widely used in submarine equipment for the oil and gas industry, which operate in an extremely adverse environment. In order to reduce the costs of these components, weld overlay cladding is employed. This process applies surface layers of nickel alloy 625 on a steel substrate by using an automatic tungsten inert gas (TIG) cladding system $^{8}$. The surface generated by this process presents some irregularities that cause variation of the depth of cut during

*e-mail: polli@utfpr.edu.br turning. This fact represents an additional complication to the machining process.

The requirements for any cutting tool material used for the machining of nickel based alloys should include: good wear resistance; high strength and toughness; high hot hardness; good resistance to thermal shock; and adequate chemical stability at elevated temperatures 9 . The development of new processing technologies is enabling the ceramic tools to fulfill these requirements. The performance of ceramic tools can be further improved by applying 20 to $40 \%$ by weight of silicon carbide to Alumina $\left(\mathrm{Al}_{2} \mathrm{O}_{3}\right)$ as a base material. This family of ceramic tools is known as whisker-reinforced ceramic tools $\left(\mathrm{Al}_{2} \mathrm{O}_{3}+\mathrm{SiCw}\right)$. The silicon carbide whiskers act as a reinforcement and remarkably increase the hardness of the ceramic tools, resulting in a $60 \%$ greater fracture resistance than the mixed oxide ceramic tools. Whisker materials are used because of the combined strength, hardness and chemical stability at high temperatures ${ }^{10}$. The SiAlON ceramic are composed of a silicon nitride base $\left(\mathrm{Si}_{3} \mathrm{~N}_{4}\right)$ combined with aluminum $(\mathrm{Al})$ and oxygen $(\mathrm{O})$. SiAlON provides excellent resistance to high temperatures, mechanical strength even when subjected to high temperatures, good thermal shock resistance and good wear resistance. Added to these characteristics, it also possesses the tenacity provided by the existence of silicon nitride in its composition ${ }^{11}$.

Many studies have been carried out about machining of alloy 718 , which is widely used in aerospace industry. However, considerably less works were reported about the machinability of alloy 625 . Although some comparison can be drawn between the two alloys in terms of machinability, the cutting conditions cannot be directly extrapolated ${ }^{12}$. Matimuthu and Baskaran ${ }^{13}$ used cemented carbide TiAlN 
coated tool for turning wrought alloy 625 under dry conditions. They found that optimum parameter setting for maximization of metal removal rate is at a cutting speed of $100 \mathrm{~m} / \mathrm{min}$, feed-rate of $0.3 \mathrm{~mm} / \mathrm{rev}$ and depth of cut of $0.75 \mathrm{~mm}$. Jahanbakhsh et al. ${ }^{14}$ investigated the effect of cutting parameters on material removal rate and tool wear of a whisker ceramic insert in turning of wrought alloy 625 . They concluded that the size of flank wear decreases with the increase in feed-rate, while the increase in depth of cut intensifies flank wear, especially, when it is associated with the increase in cutting speed. Brožek ${ }^{15}$ used using sintered carbide tools to turn alloy 625 cladded by pulsed carbon dioxide shielded surfacing technology using wire C 508. He found that the roughness of the turned surface slowly increases and that extensive deterioration occurs at the end of the tool life. Chan et al. ${ }^{8}$ utilized design of experiment to optimise the internal cylindrical rough turning for weld overlay surfaces. They found that the least flank wear was achieved by the lowest level of parameters.

As far as the authors are concerned, no studies are reported on the tool wear with ceramic tools in turning of nickel alloy 625 weld overlay. In this context, the present work investigates the use of whisker-reinforced ceramic and SiAlON tools in turning of alloy 625 clad on a steel substrate by using an automatic tungsten inert gas (TIG) cladding system.

\section{Experimental Procedure}

The workpiece material was the alloy 625 clad on AISI 4130 steel. The cladding process was performed by using a Fronius-branded FPA 9000 CC (Compact Cladding) welding system. The alloy 625 wire used was ERNiCrMo-3 with $\varnothing 1.14 \mathrm{~mm}$ according to ASME SFA-5.14. The chemical composition of the clad material is shown in Table 1. After cladding the workpiece were sent to stress-relief heat treatment.

A Mitutoyo PH-3500 profile projector was used to verify the variation of the workpiece surface profile. The difference between peaks and valleys was approximately $0.25 \mathrm{~mm}$. Thus, the depth of cut was not constant during the machining, but this value was not enough to result in an interrupt cut.

The experiments were carried out on Mazak CNC lathe, model Aland Turn $60 \mathrm{~N}$. The machining was performed using mineral-based coolant, semisynthetic and emulsifiable in concentration of $10 \%$. The cooling method was a conventional jet pressure directed at the primary shear zone accessible from the back of the chip. The experimental set-up is illustrated in Figure 1.
Whisker-reinforced $\left(\mathrm{Al}_{2} \mathrm{O}_{3}+\mathrm{SiCw}\right)$ and $\mathrm{SiAlON}$ ceramic tools were used for the tests. The specification of the inserts was RNGN 120700 . According to Richards and Aspinwall ${ }^{16}$ in general the most effective shape for ceramic inserts is a round tool because of its strength. When used in the correct depth of cut range, a round tool with its high side cutting edge angle most effectively thins out the chips, thus minimising DOC notching. The workpiece diameter was $240 \mathrm{~mm}$ and a machined length of $45 \mathrm{~mm}$ was adopted for each cutting test of the first set of experiments. The selected depth of cut was $1.50 \mathrm{~mm}$, however it varied during the machining due to the non-uniformity of the clad surface. Table 2 lists the machining parameters used for the first set of experiments.

Table 2. Experimental design matrix

\begin{tabular}{lccc}
\hline Test & $\begin{array}{c}\text { Cutting Speed } \\
(\mathbf{m} / \mathbf{m i n})\end{array}$ & Insert Grade & $\begin{array}{c}\text { Feed-Rate } \\
(\mathbf{m m} / \mathbf{r e v})\end{array}$ \\
\hline 1 & 140 & & 0.20 \\
2 & & & 0.25 \\
3 & 160 & $\mathrm{Al}_{2} \mathrm{O}_{3}+\mathrm{SiCw}$ & 0.20 \\
4 & & & 0.25 \\
5 & 180 & & 0.20 \\
6 & & & 0.25 \\
7 & 140 & & 0.20 \\
8 & & & 0.25 \\
9 & 160 & $\mathrm{SiAlON}$ & 0.20 \\
10 & & & 0.25 \\
11 & 180 & & 0.20 \\
12 & & & 0.25 \\
\hline
\end{tabular}

Afterwards a second set of experiments was carried out in order to observe tool wear behavior and the resulting workpiece microhardness at prolonged machining for the best combination of cutting parameters and tool material found in the first set of experiments. New inserts were used for each cutting test.

Tool wear evaluation was performed by using an Electron Microscopy (SEM) with Energy Dispersive Spectroscopy (EDS). Microhardness along the depth direction of the machined surface was measured using a Shimadzu HVM 2000 Microhardness Tester at a load of $490 \mathrm{mN}$ and holding time of $10 \mathrm{~s}$.

\section{Results and Discussions}

The results were completely different for the two tested insert grades. The whisker-reinforced inserts $\left(\mathrm{Al}_{2} \mathrm{O}_{3}\right.$

Table 1. Alloy 625 chemical composition (\%)

\begin{tabular}{|c|c|c|c|c|c|c|c|c|c|c|c|c|c|}
\hline Element & $N i$ & $\mathrm{Cr}$ & $\begin{array}{c}F e \\
\max .\end{array}$ & Mo & $\begin{array}{c}A l \\
\max .\end{array}$ & $\begin{array}{c}\text { Mn } \\
\max .\end{array}$ & $\underset{\max .}{C}$ & $\underset{\max }{S}$ & $\begin{array}{c}P \\
\max \end{array}$ & $N b$ & $\underset{\max .}{C o}$ & $\begin{array}{c}T i \\
\max .\end{array}$ & $\underset{\max }{S i}$ \\
\hline$(\%)$ & 58 & $20-23$ & 2.76 & $8-10$ & 0.4 & 0.5 & 0.1 & 0.015 & 0.015 & $3.15-4.15$ & 1 & 0.4 & 0.5 \\
\hline
\end{tabular}


$+\mathrm{SiCw})$ suffered catastrophic failure in the early stages of machining, making not possible a proper evaluation. However, one can observe severe notch wear on the tool flank face (Figure 2). The rapid development of the notch wear probably played an important role in the resulting fracture of the cutting tool. Bushlya et al. ${ }^{17}$ (2013) reported that chemical wear mechanisms were responsible for degradation and decomposition of whiskers when machining aged Alloy 718. They found that diffusion of $\mathrm{Ni}, \mathrm{Fe}$, and $\mathrm{Cr}$ into $\mathrm{SiC}$ whiskers degrades them and facilitates adhesion. This phenomenon also could have occurred during the tests of the present work. Moreover, high hardness and varying depths of cut along the machining due to the nonuniformity of the clad surface also contributed to the tool failure. Although whisker ceramic inserts can be used with success in turning of wrought alloy 625 , as reported by
Jahanbakhsh et al. ${ }^{13}$, it was not possible to effectively turn alloy 625 clad steel by using this tool material.

The SiAlON inserts presented better results due to their higher resistance to notch wear. As shown in Figure 3 the tool wear pattern were similar for the different cutting conditions. Wear occurred on the flank face in formation of a relative uniform flank wear and high $\mathrm{V}$-shaped notch wear. Notch wear results from a combination of aggressive conditions involved during machining process of $\mathrm{Ni}$ alloys like abrasive chips, high temperature, elevated strength and strain hardening of the workpiece maintained at high temperature.

Figure 4 shows the notch wear in function of the cutting speed and feed-rate. The cutting speed showed a larger contribution to the notch wear evolution $\left(\mathrm{VB}_{\mathrm{N}}\right)$. Initially the notch wear is high at $140 \mathrm{~m} / \mathrm{min}$, then undergoes a sudden
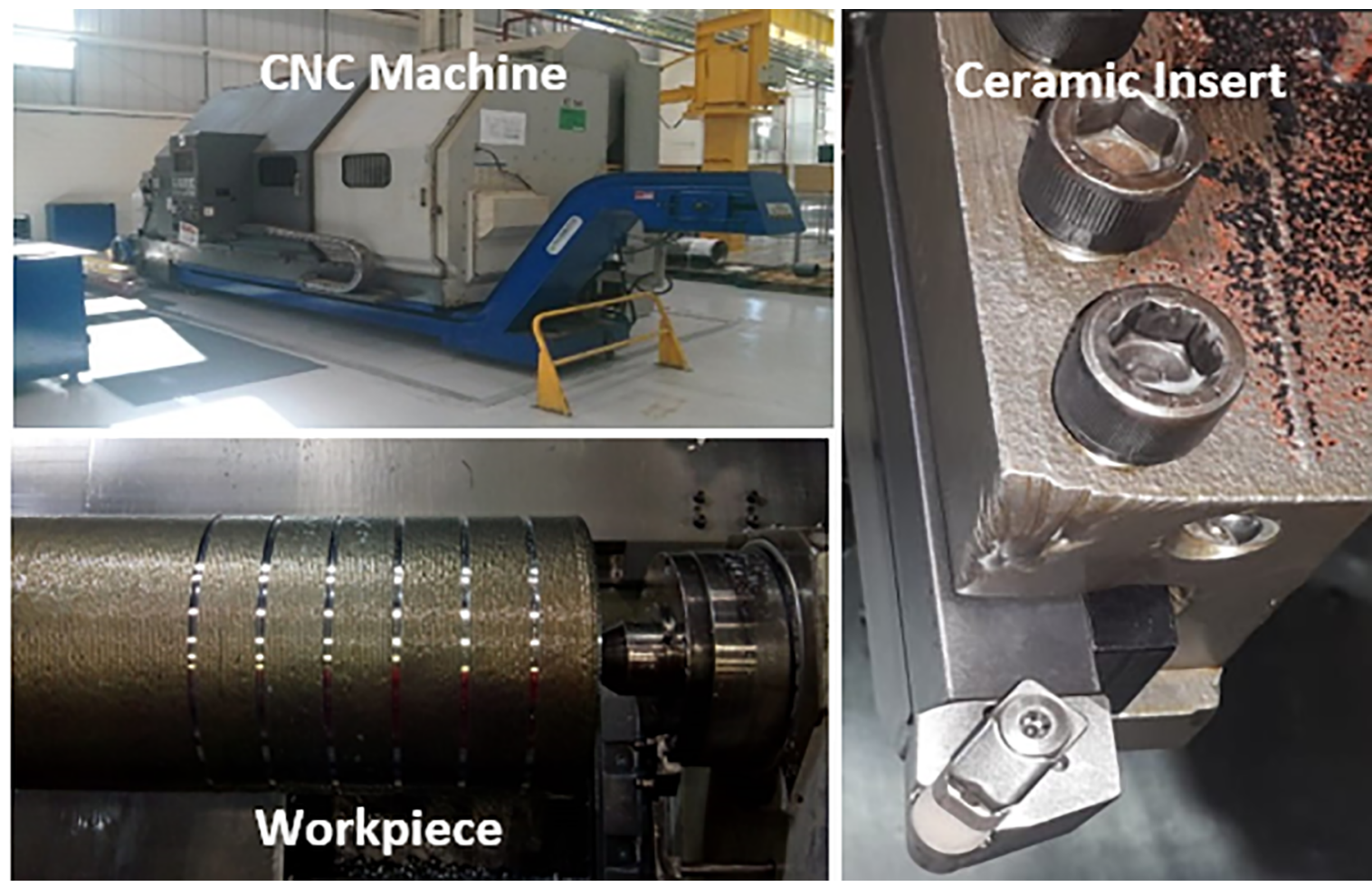

Figure 1. The experimental set-up

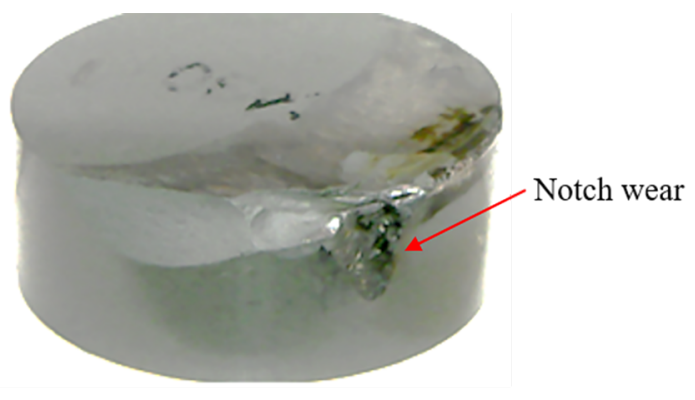

Test 3

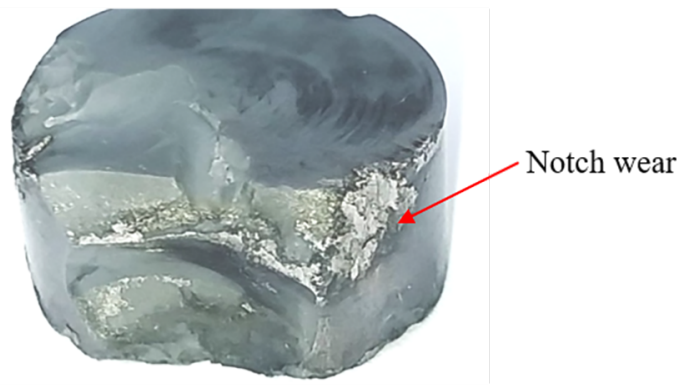

Test 4

Figure 2. Catastrophic failure of whisker-reinforced inserts 


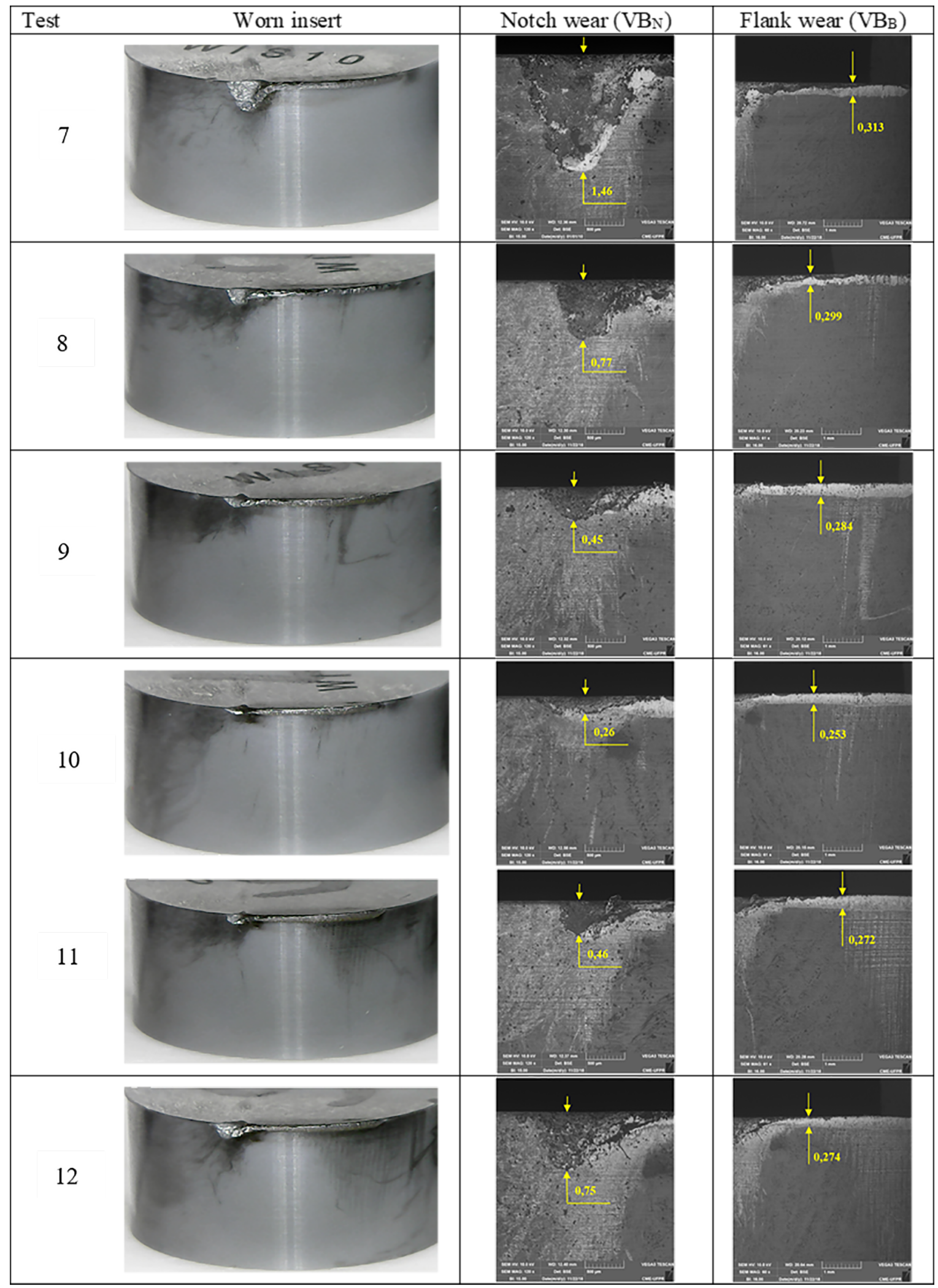

Figure 3. Worn SiAlON inserts 
fall $(160 \mathrm{~m} / \mathrm{min})$ and soon after begins to increase again at $180 \mathrm{~m} / \mathrm{min}$. There is a tendency that the higher feedrate $(0.25 \mathrm{~mm} / \mathrm{rot})$ decreases the notch wear. This may be directly related to the work-hardening tendency of nickel alloys under excessive strain loading. According to Ulutan and $\mathrm{Ozel}^{18}$ a work-hardened layer is formed in response to the machining induced deformations on the sub-surfaced and makes it extremely difficult for sequential cuts. By using a higher feed-rate during turning the alloy 625 the uncut chip thickness can be increased in such a way that it exceeds the thickness of the transient hardened layer left on the previous revolution, allowing the tool to cut more the original material and contributing to the reduction of the formation of notch wear.

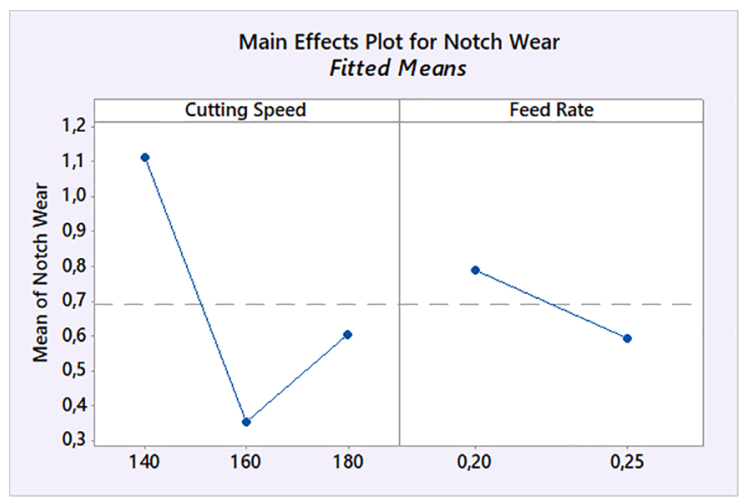

Figure 4. Notch wear in function of cutting speed and feed-rate

The greatest notch wear $\left(\mathrm{VB}_{\mathrm{N}}\right)$ was observed at the lowest cutting speed $(140 \mathrm{~m} / \mathrm{min})$ with the lowest feed-rate $(0.20 \mathrm{~m} / \mathrm{rev})$. The combination of cutting speed $160 \mathrm{~m} / \mathrm{min}$ and feed-rate $0.25 \mathrm{~mm} / \mathrm{rev}$ resulted in minor notch wear.

Small burrs formation at the depth of cut was observed in the workpieces, specially for the lowest cutting speed (Figure 5). This occurrence was identified by different researchers as one of the main causes of accelerated notch wear during machining of nickel alloys ${ }^{19-20}$. Although no large volume of burrs was generated, the material behavior influenced chip morphology and surface quality. Chip separates with a significant lateral plastic flow of workpiece material at the edge of the shear zone, causing burr formation. Nickel alloys present high hardening ratio. Consequently the formed burrs are very hard and have a furrowing effect at the height of the depth of cut, causing a large notch wear ${ }^{21}$. The use of low cutting speeds proved to be extremely harmful and propitious to this wear. In all the samples, despite the different dimensions, it was noticed that notch wear occurs at the height of the cut depth.

Figure 6 shows the flank wear in function of the cutting speed and feed-rate. The graphs are similar to the notch wear ones, however the difference between the best and worst conditions was less pronounced (about 20\%). The lowest flank wear was obtained employing cutting speed of $160 \mathrm{~m} /$ min and feed-rate of $0.25 \mathrm{~mm} / \mathrm{rev}$.

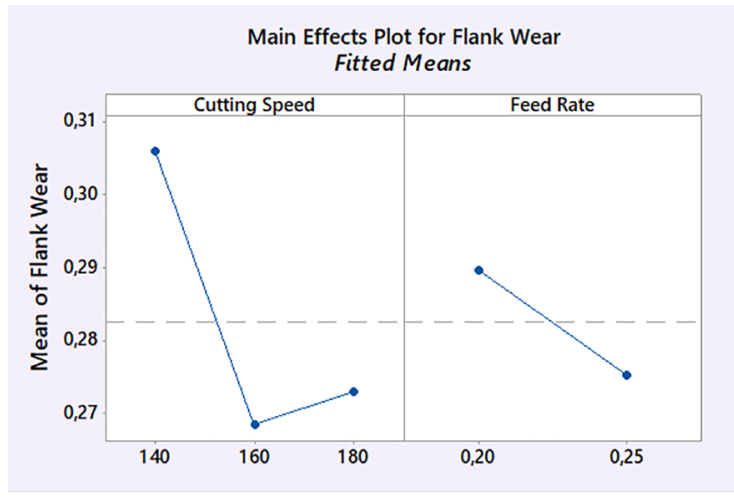

Figure 6. Flank wear in function of cutting speed and feed-rate

The SEM-EDS analysis was focused on notch wear, in order to identify the main elements of the machined alloy ( $\mathrm{Ni}, \mathrm{Cr}$ and $\mathrm{Mo}$ ) that were adhered in this region during the machining process (Table 3). EDS analysis show evidence of adhesion of the workpiece material on the flank surface of the inserts. Adhesion occurred more intensively in the sample machined with the lower cutting speed ( $140 \mathrm{~m} / \mathrm{min}$ ), where the burr formation was greater and the notch wear was the highest. According to Kong et al. ${ }^{22}$ the cutting burr generates high squeezing stress and severe rubbing action on flank face. The spaces along the groove formation provide areas for workpiece

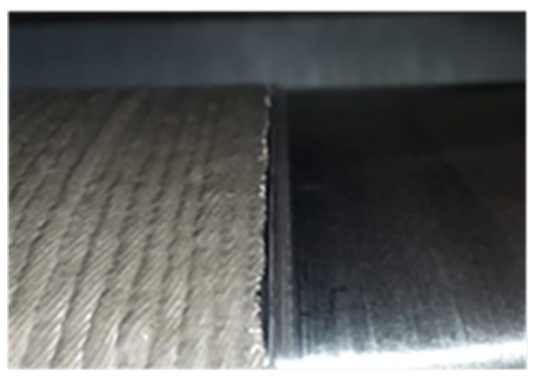

Test 4

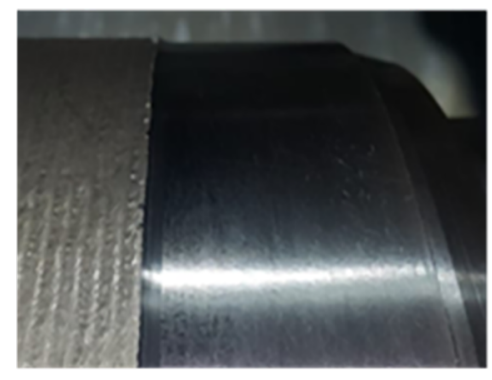

Test 6

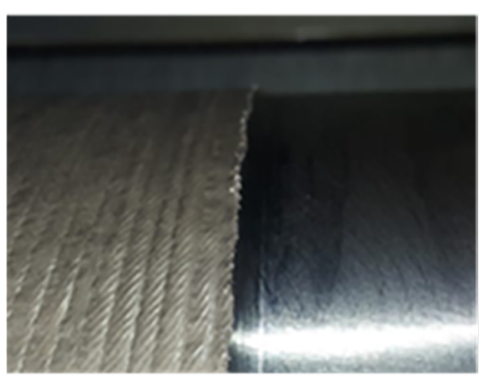

Test 8

Figure 5. Burrs formation in the machined workpieces 
material to infiltrate and then attach to the flank face. During the turning process, the cutting burr impacts the flank face and generate shearing action between the adhered interface of workpiece and tool material. When the adhered workpiece material is peeled out, it takes away parts of the tool material periodically causing even more notch wear. The cyclic adhesion and removal of workpiece/chip material from the tool, which also causes removal of tool particles characterizes the adhesive wear also called attrition wear ${ }^{23}$. As stated by Chandrasekaran and Johansson ${ }^{24}$ the notch wear development depend upon the extent of area available for adhesion, adhesive affinity between the tool and work material, the hot strength of the adhesive junction and the frequency of interruption in the adhesive contact. Therefore, this wear mechanism is expected to be encountered during machining of 625 alloy, once it has high hot strength and hence high resistance after adhesion. Moreover, the low thermal conductivity of this material is an additional negative factor, once the hot strength of the adhesive junction depend on the temperature distribution across the chip.

Table 3. EDS analysis

\begin{tabular}{lccc}
\hline Test & Ni (\%) & Cr (\%) & Mo \%) \\
\hline 7 & 10.98 & 5.40 & 2.76 \\
8 & 19.53 & 9.30 & 4.48 \\
9 & 10.86 & 4.54 & 2.72 \\
10 & 7.82 & 3.61 & 1.89 \\
11 & 8.86 & 5.19 & 2.85 \\
12 & 12.16 & 6.57 & 3.66 \\
\hline
\end{tabular}

With the increase of the cutting speed, this phenomenon was greatly reduced due to the high relative speed between chip and tool and high temperatures, which decrease the hardening effect of the burrs and made them less harmful for the cutting tool. However, with the higher cutting speed used $(180 \mathrm{~m} / \mathrm{min})$ combined with the higher feedrate, considerable dragging of the machined material was also observed.

The relationship of the flank wear versus cutting time for the best combination of cutting parameters found in the first set of experiments $\left(\mathrm{V}_{\mathrm{c}}=160 / \mathrm{min}\right.$ and $\left.\mathrm{f}=0.25 \mathrm{~mm} / \mathrm{rev}\right)$ is shown in Figure 7. Tool flank wear developed rapidly in the initial stage followed by a steady-state region until 2.5 $\mathrm{min}$, and then it grew fast and reached $0.32 \mathrm{~mm}$ at $3 \mathrm{~min}$. The progression of the notch wear was slower in the initial stage. However, after $1.5 \mathrm{~min}$ in cut the notch wear was well developed and it increased almost linearly in function of the cutting time (Figure 8). The region of notch wear depicted severe adhesion of workpiece material. EDS analysis of Table 4 shows a considerable increase in the percentage of $\mathrm{Ni}$ on the tool flank after $1.5 \mathrm{~min}$ in cut following the increase in the notch wear. After that, the percentage of $\mathrm{Ni}$ suffers small variations, which may be associated to the cyclic adhesion and removal of workpiece material from the tool related to attrition wear.

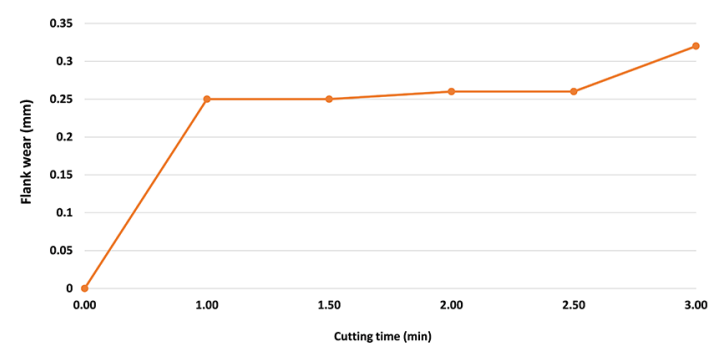

Figure 7. Flank wear in function of cutting time $(\mathrm{Vc}=160 / \mathrm{min}$ and $\mathrm{f}=0.25 \mathrm{~mm} / \mathrm{rev}$ )

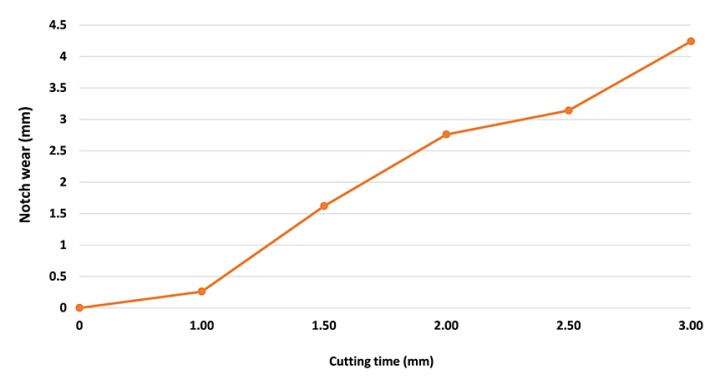

Figure 8. Notch wear in function of cutting time $(\mathrm{Vc}=160 / \mathrm{min}$ and $\mathrm{f}=0.25 \mathrm{~mm} / \mathrm{rev}$ )

Table 4. EDS analysis of worn tools for prolonged machining

\begin{tabular}{lcccc}
\hline Cutting time (s) & $\mathrm{Ni}(\%)$ & $\mathrm{Cr}(\%)$ & $\mathrm{Mo}(\%)$ & $\boldsymbol{V}(\%)$ \\
\hline 1 & 7.82 & 3.61 & 1.89 & 0.26 \\
1.5 & 15.54 & 4.61 & 0.27 & 1.62 \\
2 & 16.93 & 12.79 & 0.03 & 2.76 \\
2.5 & 11.44 & 2.63 & 0.21 & 3.14 \\
3.0 & 15.76 & 8.30 & 0.26 & 4.24 \\
\hline
\end{tabular}

Figure 9 shows that the microhardness just beneath the machined surface was found to be higher than the original workpiece material one due to the work-hardening effect. The microhardness alterations observed during machining may be due to the effect of thermal and mechanical effects. The workpiece material is subjected to work hardening, especially at high cutting temperature and pressure. This effect depends on the temperature, cutting time and the mechanism of internal stress relaxation ${ }^{25}$. However, when the depth below the machined surface increases, the hardness value starts to decrease and finally drops gradually to the bulk material hardness as shown in Figure 9. 


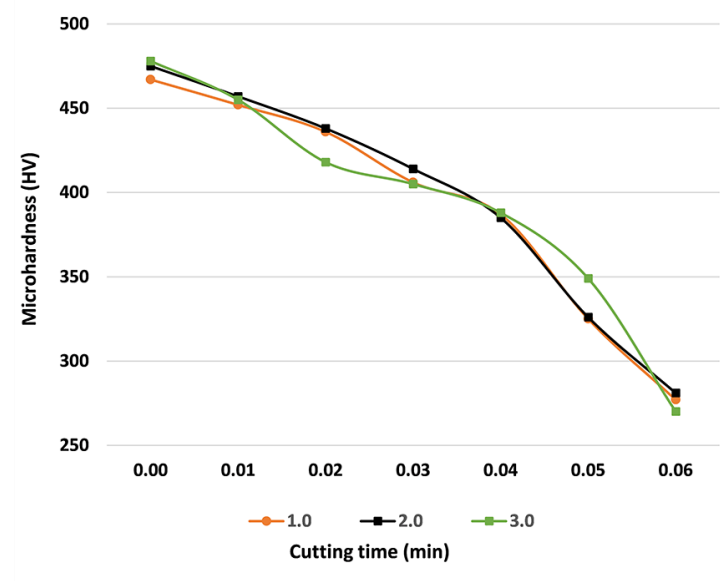

Figure 9. Evolution of microhardness of the machined surface in depth

The metallographical cross-sections of the machined surfaces show a directional orientation of the carbide particles pointing to the cutting direction (Figure 10). The images also reveal that grain deformation occurred during the cutting process resulting in work-hardening layer with non-uniform depth. According to Zhou et al. ${ }^{26}$, as the tool advanced along the working surface, dislocations in a grain are inhibited to enter the next grains due to the mismatch of deformation and grain boundaries among the different grains. Thus, many dislocations cannot stride the grain boundaries and have to pile up around these grain boundaries, resulting in the slip zone and variations in the depth of the work-hardening layer. Devillez et al. ${ }^{27}$ reported that more distorted grain morphology is found on the subsurface by the worn tool because the tool-workpiece contact area is increased due to reduced clearance angle on the tool resulting in more rubbing of the workpiece surface.
It is also possible to observe some surface damages like cavities that may be associated with the carbide particles inside the machined surface. The cutting force induces the cracks to engender around the carbide particles because they are unable to deform with the plasticized layer of the machined surface during machining. As a consequence the carbide particles break away from the machined surfaces, leaving behind cavities ${ }^{26}$. As the tool wears out more plastic deformation occurs and these surface defects become more evident as shown in Figure 10b.

\section{Conclusions}

The results of this research indicate the feasibility of the industrial application of the SiAlON inserts in rough turning of the alloy 625 clad on AISI 4130 steel, as well as the impossibility of using whiskers-reinforced ceramic tools $\left(\mathrm{Al}_{2} \mathrm{O}_{3}+\mathrm{SiCw}\right)$ in the same conditions. Considerably higher material removal rates can be achieved with SiAlON, instead of using conservative cutting parameters with coated cemented carbide tools.

Tool wear pattern of the SiAION inserts were similar for the different cutting conditions. Wear occurred on the flank face in formation of a relative uniform flank wear and high V-shaped notch wear. The highest flank and notch wear were observed for the lowest cutting speed $(140 \mathrm{~m} / \mathrm{min})$, which induced the formation of burrs in the workpiece at the depth of cut. Adhesion occurred more intensively at this condition. The least flank and notch wear were achieved by using cutting speed of 160 $\mathrm{m} / \mathrm{min}$ and feed-rate of $0.25 \mathrm{~mm} / \mathrm{rev}$. Prolonged turning with worn tools resulted in microstructural alterations of the workpiece material and surface damages like cavities that may be associated with the carbide particles inside the machined surface. (a)

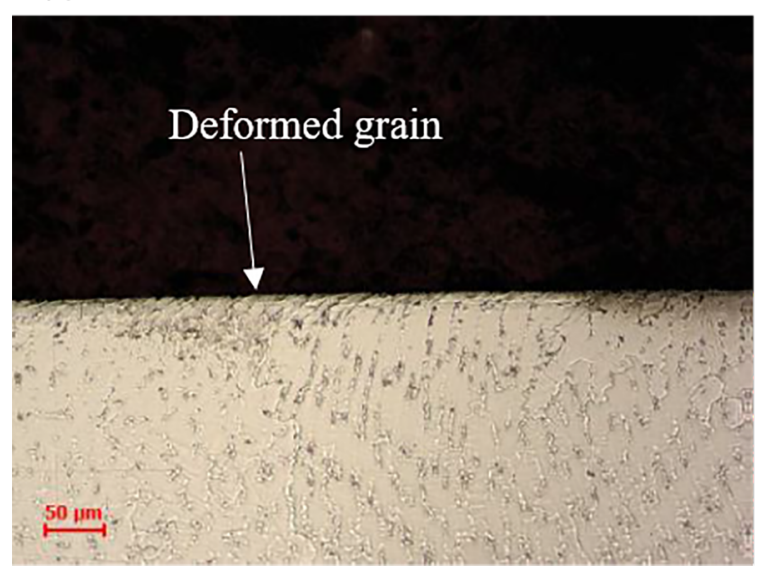

(b)

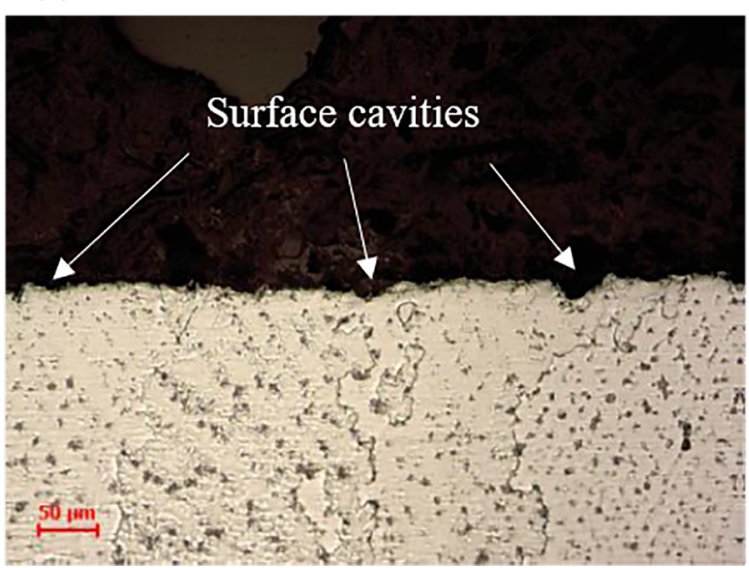

Figure 10. Metallographical cross-sections of the machined surfaces at cutting time (a) 1 min and (b) 3 min 


\section{References}

1. Reed RC. The superalloys: fundamentals and applications. Cambridge: Cambridge University Press; 2006.

2. Youssef HA. Machining of stainless steels and super alloys: traditional and nontraditional techniques. Chichester: John Wiley \& Sons; 2016.

3. Jang DY, Watkins TR, Kozaczek KJ, Hubbard CR, Cavin OB. Surface residual stresses in machined austenitic stainless steel. Wear. 1996;194(1-2):168-173.

4. Korkut I, Kasap M, Ciftci I, Seker U. Determination of optimum cutting parameters during machining of AISI 304 austenitic stainless steel. Materials and Design. 2004;25(4):303-305.

5. Tekiner Z, Yesilyurt S. Investigation of the cutting parameters depending on process sound during turning of AISI 304 austenitic stainless steel. Materials and Design. 2004;25(6):507-513.

6. Ezugwu EO, Bonney J. Effect of high-pressure coolant supply when machining nickel-base, Inconel 718, alloy with coated carbide tools. Journal of Materials Processing Technology. 2004;153-154:1045-1050.

7. Nickel Development Institute (NiDI). Machining nickel alloys - Reference Book $n^{o} .11$ 008. Netherlands: NiDI; 1992.

8. Chan L, Shyha I, Dreyer D, Hamilton J, Hackney P. Process optimisation for internal cylindrical rough turning of nickel alloy 625 weld overlay. International Journal of Chemical, Molecular, Nuclear, Materials and Metallurgical Engineering. 2017;11(4): 273-277.

9. Ezugwu EO, Wang ZM, Machado AR. The machinability of nickel-based alloys: a review. Journal of Materials Processing Technology. 1999;86(1-3):1-16.

10. Wertheim R, Layyous A, Harpaz J. Development and application of new cutting tool materials. In: Proceedings of the Conference on Improving Machine Tool Performance; 1998 jul. San Sebastian, Spain: CIMTP; 1998. p. 303-313.

11. Groover MP. Fundamentals of modern manufacturing: materials, processes, and systems. Chichester: John Wiley \& Sons; 2012.

12. Turner S, Taylor M, Etxeberria A, Arrazola P. Machinability of the Nickel Alloys Inconel 625 and 718. In: 23rd AeroMat Conference and Exposition; 2012 may 23-25. Charlotte, NC, USA: AeroMat; 2012.

13. Matimuthu P, Baskaran R. Optimal setting of machining parameters for turning Inconel 625 using coated tool. Applied Mechanics and Materials. 2014;573:632-637.
14. Jahanbakhsh M, Farid AA, Lotfi M. Optimal flank wear in turning of Inconel 625 super-alloy using ceramic tool. Journal of Engineering Manufacture. 2018;232(2):208-216.

15. Brožek M. The turning of overlays using sintered carbide tools. The International Journal of Advanced Manufacturing Technology. 2009;40(5-6):438-446.

16. Richards N, Aspinwall D. Use of ceramic tools for machining nickel based alloys. International Journal of Machine Tools and Manufacture. 1989;29(4):575-588.

17. Bushlya V, Zhou JM, Avdovic P, Stahl JE. Wear mechanisms of silicon carbide-whisker-reinforced alumina $\left(\mathrm{Al}_{2} \mathrm{O}_{3}-\mathrm{SiCw}\right)$ cutting tools when high-speed machining aged Alloy 718. The International Journal of Advanced Manufacturing Technology. 2013;68(5-8):1083-1093.

18. Ulutan D, Özel T. Machining induced surface integrity in titanium and nickel alloys: a review. The International Journal of Machine Tools and Manufacture. 2011;51(3):250-280.

19. Kitagawa T, Kubo A, Maekawa K. Temperature and wear of cutting tools in high-speed machining of Inconel 718 and Ti-6Al-6V-2Sn. Wear. 1997;202(2):142-148.

20. Xiao M, He N, Li LJ. Modeling notch wear of ceramic tool in high speed machining of Nickel-based superalloy. Journal of Wuhan University of Technology - Materials Science Edition . 2010;25(1):78-83

21. Diniz AE, Machado AR, Corrêa JG. Tool wear mechanisms - in the machining of steels and stainless steels. The International Journal of Advanced Manufacturing Technology. 2016;87:3157-3168.

22. Kong J, Xia Z, Xu D, He N. Investigation on notch wear mechanism in finish turning pure iron material with uncoated carbide tools under different cooling/lubrication conditions. The International Journal of Advanced Manufacturing Technology. 2016;86:97-105.

23. Trent EM, Wright PK. Metal cutting. Oxford: ButterworthHeinemann; 2000.

24. Chandrasekaran H, Johansson JO. Chip flow and notch wear mechanisms during the machining of high austenitic stainless steels. CIRP Annals - Manufacturing Technology.1994;43(1):101-105.

25. Ginting A, Nouari M. Surface integrity of dry machined titanium alloys. International Journal of Machine Tools and Manufacture. 2009;49(3-4):325-332.

26. Zou B, Chen M, Huang C, An Q. Study on surface damages caused by turning NiCr20TiAl nickel-based alloy. Journal of Materials Processing Technology. 2009;209(17):5802-5809.

27. Devillez A, Coz GL, Dominiak S, Dudzinski D. Dry machining of Inconel 718, workpiece surface integrity. Journal of Materials Processing Technology. 2011;211(10):1590-1598. 